Infants at higher risk of the Sudden Infant Death Syndrome (SIDS) can be successfully detected and protecteu during the first year of life. From March 1977 to February 1988, 150 infants have been investigated for high risk of SIDS. There were 30 Near Miss infants, all successfuliy ressuscitated (Group I), 35 siblings of Sids victims ( 3 twins) (Group II), and 85 infants referred after an episode of palldr or cyanosis related to sleep (Group III). Al 1 were subjected to a mean of 2 night polygraphic recording of sleep stages, respiratory and heart rates as we 11 as Ptco2. The infants from Groups I and III were also studied for a recognizable cause of the initial incident. 32 infants were considered at higher risk:every Near Miss (after exclusion of recognizable causes), one infant from Group II (abnormal polygraphic recording), and one from Group III (exclusion of recognizable causes and abnormal polygraphic recording). They were sent home with a cardiorespiratory monitoring. They all required stimulation by the parents for apnea or bradycardia,but there was no death. Among the 118 infants not considered at higher risk, none presented any incident.A11 150 infants are well by now.

Département de Pédiatrie. Honital Universitaire SaintPierre. Rue Haute, 322, 1000 - Bruxelles. Belgium.
A.WILKINSON, ${ }^{\star}$ PJOHNSON, E.CARSE, P.WHYTE,"D, HENDERSON-SMARI' Department of Paediatrics and Nuffield Institute for Medical Research, Oxford University, England.

Regulation of Breathing and Transcutaneous Oxygen in Infants during Sleep from birth to 6 months.

Polygraphic studies lasting 6 hours were made sequentially at 1 week, 1,3 and 6 months in 14 infants $(9$ normal and 5 sibs of sudden infant death-SIDS). Heart and respiratory rate (HR, RR), transcutaneous oxygen $\left(\mathrm{P}_{t C} \mathrm{O}_{2}\right)$, and the incidence of apnoea,bradycardia and periodic breathing was compared at each age. HR and RR were higher in active sleep(AS) than in quiet sleep(QS) at all ages In normal babies RR did not change with age but in the sibs of SIDS it was higher at 1 week and 1 month ( $\mathrm{P}<0.05) . \mathrm{P}_{t C} \mathrm{O}_{2}$ rose in the normal babies between 1 week and 1 month and in the sibs of SIDS between 1 week, and 3 months ( $\mathrm{P} 0.05$ ). There was no difference in mean $\mathrm{PtCO}_{2}$ between $\mathrm{AS}$ and $Q S$ at any age and the level was not different between groups at 1 month when the sibs of SIDS had a higherRR. The hypothesis that this group suffers chronic mild hypoxia is not supported(1). In normal babies between 1 week and 1 month the incidence of apnoea (3-5 secs) decreased in AS but increased in QS. Apnoea 6 secs was rare but most cormon at 1 week. No apnoea $>11$ secs was recorded.Bradycardia ( $100 \mathrm{bpm}$ ) acoompanied 78 of apnoic episodes at 1 week, this increased to $15 \%$ at 3 months but was absent at 6 months.Episodes of periodic breathing were most frequent at 1 month and then decreased progressively at 3 and 6 months. From birth to 6 months the mechanisms which control breathing develop with a separate time sequenoe for different sleep states.

1. Hopenbrouwers I.T. et al Ped. Res. 10:425.1976.

Th.Angerpointner*, O.L1nderkamp, H.Stal11nger*, K.P.Rlegel (Dept.Paediat.Surg.and Div.Neonatol. Univ.Children's Hospital, Munich, FRG)

\title{
79
}

Circulatory adaptation to hypoxaemia during anaesthesia and surgery in newborn and two weeks old piglets

When piglets were subjected to anaesthesia and surgery (placing electromagnetic flow-probes around the ascending aorta) and additionally in part, to hypoxia ( $\mathrm{PaO}_{2}$ lowered from $60-100$ Torr $[8-13.3 \mathrm{kPa}]$ to $30-40 \operatorname{Torr}[4-5.3 \mathrm{kPa}]$ by chang1ng $\mathrm{Flo}_{2}$ ), a remarkably uniform response of the cardiovascular system could be observed: Soon after the beginning of the experiment cardiac performance increased by $12-35$ percent $(p<0.01)$ within $15-30 \mathrm{~min}$. This was followed by a fatal decrease leading to cardiac failure sccompanied by increasing metabolic acidosis.

In three groups mean survival time was approximately three hours: In the hypoxaemic newborns $(n=10)$, in both the normoxaemic $(n=8)$ and the hypoxaemic piglets two weeks of age $(n=8)$. The normoxaemic newborns $(n-8)$, however, survived significantly longer $(416 \pm 167 \mathrm{~min} ; \mathrm{p}<0.001)$, and all the changes occured later. Survival time depended on $\mathrm{pH}$ decrease per hour in all groups and on the extent of the increase of heart rate in both hypoxaem1c groups.

We conclude from our experiments that newborn and two weeks old piglets cannot sustain hypoxaemla of this degree longer than $30 \mathrm{mln}$. Newborn piglets tolerate anaesthesla and surgery, not complicated by hypoxaemia, better than two weeks old animals.

80

SERUM FERRITIN(SF) MEASUREMENTS IN CHILDREN BY A NEW IMMUNORADIOMETRIC ASSAY

Mi1ller-Wiefel,D.E. ,* Brandeis,W.E.*Bendlein, F* Schärer,K.,University Children's Hospital, Heidelberg,FRG

The immunoradiometric assay(IRMA) for determination of SF can be ameliorated by use of a heterologous antibody $(A B)$ system with a solid phase $A B$ directed against liver and a $\mathrm{J}^{125}$ labelled $A B$ against placenta ferritin. We investigated 65 control subjects (age 1-21 yrs) without reduced $\mathrm{Hb}, \mathrm{MCH}, \mathrm{MCV}$ and transferrin saturation, 10 children with iron (Fe) deficiency anemia without increased sedimentation rate or serum transaminases (A), 10 children with latent Fe deficiency(B), and 86 children with other disturbances of Fe metabolism: chronic renal
failure under conservative (C) or dialysis (D) treatment and polytransfused non-renal anemia (E). Geometric mean(MG) and extreme limits of $\mathrm{SF}$ in controls increased with age: $23-102 \mathrm{\mu g} / 1$ at $1-5 \mathrm{yrs}, 31-190$ at $6-13 \mathrm{yrs}$, 39-292 at 14-20 yrs (MG of all: $66 \mu \mathrm{g} / 1$ ). These values are higher than SF in normal children reported with for(1- SF in $A$ was always lower than in controls $(1-13 \mu \mathrm{g} / 1)$. Intermediate values were obtained in $\mathrm{B}(14-23$ $\mathrm{ug} / 1)$. SF showed a wide range in C $(7-406 \mu \mathrm{g} / 1, \mathrm{MG} 69)$ and was significantly higher in D (MG $553 \mu \mathrm{g} / \mathrm{l}$ ) and $\mathrm{E}$ (MG $3509 \mu \mathrm{g} / 1$ ). The highly sensivitive new IRMA enables a reliable differentiation between various states of $\mathrm{Fe}$ leficiency and overload.

81 nates. Kinderklinik der Medizinischen Hochschule Hannover, 3 Hannover 6l, W.-Germany.

The effect of transplacental antibody on the 1mmunresponse to Bovine Serum Albumin (BSA) normally present in infant formulas was assessed in 15 heal thy neonates. Anti-BSA, determined by the Farr-assay using Ing ${ }^{+}$I-BSA$\mathrm{N} / \mathrm{ml}$, was considered present if sera bound $>10 \%$ of $\mathrm{I}$ BSA. If $>25 \%$ of I-BSA was bound, an antigen-bindingcapacity (ABC) was calculated and expressed as ng BSA-N bound by $1 \mathrm{ml}$ of serum. 7 infants (group I) with antiBSA in their cordblood were compared to 8 infants without passive anti-BSA (gr. II). The development of antishown in the table.

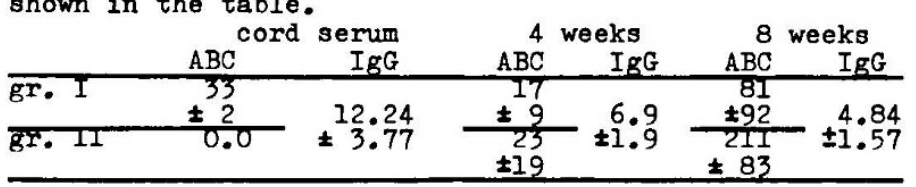

The finding of a slgnificantly higher ABC in gr. II (at 8 weeks $p=0.05$ ) suggests that passive antibody may modify the response to oral antigens although it does not prevent active antibody formation in early ilfe. Supported by DFG-Grant RI $345 / 1$.

82 LOWE' SYNDROME

F. HANEFELD, TH. LENNERT, Dept. of Pediatrics, and G. STOLTENBURG, Dept. of Neuropath., Free University
of Berlin, Berlin-West, F.R.G. CONGENITAL MYOPATHY IN

\section{The oculo-} an $x$-linked disorder charecterized by bilateral congenital cataracts, mental deficiency, growth retardation, muscular hypotonia, proteinuria, generalized aminoaciduria, metabolic acidosis and rickets. At present no basic biochemical lesion is known to explain this variety of abnormalities. We would like to report two cases in whom there is evidence of a muscular disorder as a possible cause of the hypotonia. Both cases showed the typical symptorns of Lowe syndrome, one was the second affected child. In addition to muscular hypotonia which improved over the years both patients show constantly elevated CPK levels up to 254 and $174 \mathrm{U} / 1$ respectively. Muscular biopsy taken at herniotony revealed definite myopathy with small muscle fibers, variation in fibre size and single fiber necrosis. These findings explain the muscular hypotonia observed in our patients. Some investigators, however, were unable to demonstrate convincing myopathic changes in their cases. They considered the hypotonia as a neuropathic phenomenon probably resulting from an unknown metabolic derangement. Further neuromuscular studies of more cases are necessary to answer this question. It might, however, turn out, that Lowe syndrome is not an entity and that cases with myopathy form just a special group. If one considers this disease as a membrane or transport disorder the myopathy is of great interest. 